Check for updates

Cite this: RSC Adv., 2018, 8, 10396

Received 19th January 2018

Accepted 5th March 2018

DOI: $10.1039 / c 8 \mathrm{ra00519b}$

rsc.li/rsc-advances

\section{Typical pharmaceutical molecule removal behavior from water by positively and negatively charged composite hollow fiber nanofiltration membranes}

\author{
Xiuzhen Wei, (iD) ab Xiaoyan Bao, ${ }^{\text {ab }}$ Jiawei Wu, ${ }^{\text {ab }}$ Cuixia Li, ${ }^{\text {ab }}$ Yingying Shi, ${ }^{\text {ab }}$ \\ Jinyuan Chen, *ab Bosheng Lv*ab and Baoku Zhu iD c
}

\begin{abstract}
The rejection behaviors of two different charged composite hollow fiber nanofiltration (NF) membranes for six pharmaceutical molecules, primidone, carbamazepine, sulfamethoxazole, atenolol, sulfadimidine and norfloxacin, were characterized in this study. The saturation adsorption behaviors of the different pharmaceutical molecules on each membrane surface were studied and found to be related to the molecular weight, charge and hydrophilicity of the pharmaceutical molecules. After the pharmaceutical molecules reached adsorption equilibrium, the rejection rates of different NF membranes were characterized. The rejection rates of primidone, carbamazepine, sulfamethoxazole, atenolol, sulfadimidine and norfloxacin by the PEI-NF membrane were $85.6 \%, 91.8 \%, 79.9 \%, 98.1 \%, 93.3 \%$, and $97.1 \%$, respectively. Meanwhile, the rejection rates of the pharmaceutical molecules by the PIP-NF membrane were $82.2 \%, 85.4 \%, 91.5 \%, 79.1 \%, 87 \%$ and $93.3 \%$, respectively. The influence of feed concentration, operation pressure, temperature, $\mathrm{pH}$ and ionic strength on the rejection behaviors of the different charged NF membranes were also studied.
\end{abstract}

\section{Introduction}

In recent decades, pharmaceuticals and personal care products (PPCPs) have caused wide public concerns as so-called emerging contaminants. ${ }^{\mathbf{1 - 4}}$ PPCPs are primarily used in human health, veterinary medicine, agriculture, cosmetic and personal care, drugs (antibiotics, anti-inflammatory, antiepileptic, painkiller, sedative, etc.), fragrances, sunscreen, X-ray contrast media, etc. ${ }^{5}$ Most PPCPs are easy to dissolve in water, have high bioactivity and high polarity. ${ }^{4}$ PPCPs can migrate and diffuse in the environment along the water cycle and food chain. ${ }^{6}$ PPCPs have been detected frequently in different water areas all over the world at concentrations of $\mathrm{ng} \mathrm{L}^{-1}$ to $\mu \mathrm{g} \mathrm{L}^{-1}$. $^{6-10}$ PPCPs are called "pseudo-persistent" contaminants because their continuous discharge into the environment results in a certain concentration in the environment, though many PPCPs have a short half-life. ${ }^{5}$ The source of PPCPs in environmental water is closely related to human activities. The main way in which PPCPs are introduced into environmental water include individual household use, hospital discharges, the

${ }^{a}$ College of Environment, Zhejiang University of Technology, Hangzhou 310014, China. E-mail: xzwei@zjut.edu.cn; cjy1128@zjut.edu.cn; zjhzlbs@zjut.edu.cn; Fax: +86571 88320054; Tel: +8657188320054

${ }^{b}$ Key Laboratory of Microbial Technology for Industrial Pollution Control of Zhejiang Province, China

${ }^{c} M O E$ Key Laboratory of Macromolecular Synthesis and Functionalization, Zhejiang University, China direct discharge of agriculture, stock farming and aquaculture, and ineffective industrial wastewater treatment., ${ }^{5,11}$ Currently, more than 6 million varieties of pharmaceuticals are used by humans and animal in the world, ${ }^{12}$ and the yearly output of PPCPs is up to one million tons. The persistence and high bioactivity of pharmaceuticals in the water could produce potentially damaging effects for environmental ecosystems, such as long-term antibiotic resistance on aquatic organisms and serious health effects on human and animals through enrichment along the food chain. ${ }^{13-15}$ More seriously, traditional water and wastewater treatment technology could not remove or degrade the PPCPs molecules. So, we need to seek for relatively new treatment technology to solve the more and more serious question.

Membrane separation technologies are relative new water treatment technology and have been widely applied in water treatment areas, which are not only used in industrial wastewater disposal such as electroplating wastewater, dyeing wastewater but also used in treatment of urban sewage and drinking water. ${ }^{\mathbf{1 6 - 2 1}}$ Compared with the traditional water treatment technologies, membrane technologies need less space, have a relatively lower investment, are relatively easier to operate, have a lower energy consumption and produce less waste. Additionally, nanofiltration (NF) hollow fiber membranes exhibit both the advantages of hollow fiber membranes and NF membranes. Compared with flat-sheet membranes, hollow fiber membranes have the advantages of easy preparation, less land occupation, easy maintenance and the lack of a need for 
a support. NF membranes have a molecular weight cut-off of 200-2000 Da (ref. 22) and can effectively reject organic molecules with a molecular weight of approximately $200 \mathrm{Da}$. The surface charge of NF membranes can be changed according to the separation aim and they can be prepared with reactive monomers. Although both NF and reverse osmosis (RO) membranes can reject small organic molecules, the operation pressure of NF membrane is noticeably lower than that of RO membranes, which means that NF membranes can save on energy consumption. Several studies have been published investigating the mechanisms of pharmaceutical molecule rejection by NF membranes. ${ }^{23,24}$ However, studies about positively charged hollow fiber NF membranes are relative few. $\mathrm{Can}^{25}$ prepared positively charged NF hollow fiber membranes by crosslinking polyethyleneimine (PEI) on polyimide hollow fiber substrate. The membrane showed great potential in treating highly concentrated wastewater from dye manufacture. The newly developed polyamide-imide (PAI) hollow fiber NF membrane showed satisfactory rejections (average: $>90 \%$ ) when it was used to treat wastewater from dye manufacture. ${ }^{26} \mathrm{Wang}^{27}$ developed dual layer positively charge hollow fiber NF membranes by crossing PAI and the NF membranes showed relative high water permeability $\left(15.8 \mathrm{~L} \mathrm{~m}^{-2} \mathrm{~h}^{-1} \mathrm{bar}^{-1}\right)$.

Compared with neutral membranes, charged membranes have become increasingly promising in energy conservation, separation efficiency and other aspects. In addition to their physical screening ability based on pore size, there also exists a unique Donnan effect for charged NF membranes. This effect can separate components by electrostatic adsorption and charge repulsion, which makes it possible to adsorb and separate small size components using relatively large pore size NF membranes or to separate components with the same particle size but different charge properties. Because of these properties, charged membranes are pervasively used in many industrial fields, such as the separation of concentrated dye or biological macromolecules, treatment of cathodic electrophoretic paint waste liquor, the removal of bacterial endotoxin in medicine liquor and even pure water. ${ }^{28,29}$ The hydrophilic and antifouling properties of charged NF membranes was also enhanced due to the modification of charged groups. At the same time, the permeable capacity of the charged NF membranes was also increased significantly due to the electrostatic effects of different charged groups. The separation mechanism of NF membranes is mainly steric hindrance and electrostatic repulsion, which is related with membrane pore size and membrane surface charge, ${ }^{21}$ respectively. So, we prepared positively and negatively charged NF membranes to investigate the effect of membrane surface charge on the NF rejection behavior for typical pharmaceutical molecules.

In this study, both negatively charged and positively charged NF hollow fiber membranes were prepared in our lab and used to remove pharmaceutical molecules from water. The six pharmaceuticals used are primidone, carbamazepine, sulfamethoxazole, atenolol, sulfadimidine and norfloxacin. Adsorption kinetic behaviors of the six pharmaceuticals molecules on NF membranes were studied and compared. The effect of feed concentration, operation pressure, temperature, $\mathrm{pH}$ and ionic strength on the removal behavior of the six pharmaceuticals by both NF membranes was also investigated.

The six pharmaceuticals, which are typical PPCPs, are used widely but hard to remove from the environmental water. For example, the removal rate of carbamazepine (CBZ) in sewage treatment plants is less than $50 \% .^{30}$ Therefore, CBZ is frequently detected in surface water, groundwater and drinking water, and its concentration is relative high. At present, CBZ has been identified as a new type of pollutant and monitoring object in Germany, and its water quality standards have also been formulated. Furthermore, the chosen six pharmaceuticals have different molecular weights and show different charges in aqueous solution.

\section{Methodology}

\subsection{Materials}

The charged NF hollow fiber membranes of PEI-NF membrane and PIP-NF membrane were prepared in our lab ${ }^{\mathbf{2 0 , 2 1}}$ by interfacial polymerization. The PEI-NF membrane was prepared using polyethylenimine (PEI) and trimesoyl chloride (TMC) as active monomers on polysulfone/polyethersulfone (PS/PES) ultrafiltration hollow fibers membranes. The PIP-NF membrane was prepared using piperazine (PIP) and TMC as reactive monomers on PS/PES supporting membranes. First, PEI or PIP $(0.75 \mathrm{wt} \%$ PEI aqueous solutions or $2.0 \mathrm{w} / \mathrm{v} \%$ PIP with $1.0 \mathrm{w} / \mathrm{v} \% \mathrm{Na}_{3} \mathrm{PO}_{4}$ as the acid acceptor) was infused into the inner surface of the PS/ PES UF membranes and left to sit for $10 \mathrm{~min}$. Next, a $0.5 \mathrm{wt} \%$ TMC solution in $n$-hexane was poured into the inner surface of the support hollow fibers and left for $20 \mathrm{~s}$ (for PIP-NF membrane it is $50 \mathrm{~s}$ ). After removing the excess solution, the resultant $\mathrm{NF}$ membrane underwent heat treatment in a drying oven at $60{ }^{\circ} \mathrm{C}$ for $10 \mathrm{~min}$ to complete the interfacial polymerization reaction. Thus, a virgin NF membrane was obtained. The characteristics of the PEI-NF and PIP-NF membrane are shown in Table 1. Table 2 shows the characteristics of target pharmaceuticals studied. The pharmaceuticals, primidone, carbamazepine, sulfamethoxazole, atenolol, sulfadimidine and norfloxacin, were

Table 1 Characteristics of the hollow fiber NF membranes used in this study ${ }^{20,21}$

\begin{tabular}{|c|c|c|c|c|c|c|}
\hline Membrane & Material & MWCO (Da) & $\begin{array}{l}\text { Pure water flux } \\
\left(\mathrm{L} \mathrm{m}^{-2} \mathrm{~h}^{-1}\right)\end{array}$ & IEP & $\mathrm{pH}$ & Contact angle $\left({ }^{\circ}\right)$ \\
\hline PEI-NF & Polyamide & 500 & 42 & 8.2 & $2-11$ & 50.1 \\
\hline PIP-NF & Polyamide & 520 & 47.5 & 6.6 & $2-11$ & 71.1 \\
\hline
\end{tabular}


Table 2 Main property parameters of the pharmaceuticals used in the study

\begin{tabular}{|c|c|c|c|c|c|}
\hline Pharmaceuticals & Chemical structures & Molecular formula & Molecular weight & $\mathrm{p} K_{\mathrm{a}}$ & $\log K_{\text {ow }}$ \\
\hline Primidone & & $\mathrm{C}_{12} \mathrm{H}_{14} \mathrm{~N}_{2} \mathrm{O}_{2}$ & 218.25 & 13.0 & 0.91 \\
\hline Carbamazepine & & $\mathrm{C}_{15} \mathrm{H}_{12} \mathrm{~N}_{2} \mathrm{O}$ & 236.27 & $2.3,13.9$ & 2.45 \\
\hline Atenolol & & $\mathrm{C}_{14} \mathrm{H}_{22} \mathrm{~N}_{2} \mathrm{O}_{3}$ & 266.34 & 9.6 & 0.16 \\
\hline Sulfadimidine & & $\mathrm{C}_{12} \mathrm{H}_{14} \mathrm{~N}_{4} \mathrm{O}_{2} \mathrm{~S}$ & 278.33 & $2.65,7.65$ & 0.89 \\
\hline
\end{tabular}

purchased from Aladdin Reagent Co., Shanghai, China, with more than $99 \%$ purity. The pharmaceuticals have different molecular weights, structures and varied charge at different $\mathrm{pH}$ values. HPLC-grade $n$-hexane, methanol, acetonitrile and ethanol were obtained from Aladdin Reagent Co., Shanghai, China. All other chemicals are analytic grade and supplied by Aladdin Reagent Co., Shanghai, China. Deionized water (DI) used in the experiment was treated with reverse osmosis membranes and ion exchange resin.

\subsection{Membrane performance evaluation}

The rejection behavior of different pharmaceutical molecules by NF membranes was evaluated by a lab-scale cross-flow filtration apparatus at a constant flow rate of $1.1 \mathrm{~L} \mathrm{~min}^{-1}$ in a batch circular mode. Both the concentrated and permeated solution recycled back to a feed tank to keep the feed concentration constant. For different NF membranes modules, the effective area is approximately $23 \mathrm{~cm}^{2}$. Prior to the NF properties evaluation, all NF hollow fiber membranes were pre-pressurized under 0.5 $\mathrm{MPa}$ for $1 \mathrm{~h}$ with DI water to make sure the membranes were in a stable state. Then the performances of different NF membranes were studied under 0.4 MPa unless noted especially.

Adsorption experiments were carried out at the conditions of $25{ }^{\circ} \mathrm{C}, \mathrm{pH}=7$ and $0.4 \mathrm{MPa}$ without electrolyte. Both the feed and permeate concentrations of the pharmaceuticals were measured at specified intervals of filtration time. After reaching adsorption equilibrium, the permeate flux and rejection rates of the six pharmaceuticals by both the PEI-NF and PIP-NF membranes at different operation conditions (feed concentration, temperature, pressure, $\mathrm{pH}$ and ionic strength) were also investigated to research the rejection mechanism of the different charged membranes. All experiments were carried out at least three times, and a mean was calculated to reduce any discrepancies.

The stability of the NF membrane performance was studied at $0.4 \mathrm{MPa}, 25{ }^{\circ} \mathrm{C}$ with a neutral solution under continuous filtration for 7 days using a $1000 \mu \mathrm{g} \mathrm{L}^{-1}$ carbamazepine solution as the feed.

\subsection{Characterization of the membranes}

2.3.1. Surface zeta potential measurement. Surface charge properties of the PEI-NF and PIP-NF membranes were studied 
by measuring streaming potentials of the membranes at various pH values using a SurPASS electrokinetic analyzer (Anton Paar $\mathrm{GmbH}$, Austria) to determine the isoelectric point (IEP). Measurements were performed under $0.4 \mathrm{MPa}, 25.0{ }^{\circ} \mathrm{C}$ with $0.001 \mathrm{~mol} \mathrm{~L}^{-1}$ aqueous $\mathrm{KCl}$ solutions, and the $\mathrm{pH}$ ranged from 5 to 12 and 3 to 10 for the PEI-NF and PIP-NF membranes, respectively. When the streaming potential was obtained, the surface zeta potential was determined according to the Helmholtz-Smoluchowski equation.

\subsection{Analytical method}

All samples were determined by an Agilent Technologies 1200 series HPLC with an Aglient Eclipse XDB-C18 $150 \mathrm{~mm} \times 4.6$ $\mathrm{mm}, 5 \mu \mathrm{m}$ column. The detector of HPLC is DAD. Each pharmaceutical had its own sampling methods, which are described as follows.

Primidone. Detection wavelength of $215 \mathrm{~nm}$, sample injection volume of $20 \mu \mathrm{L}$, mobile phase composed of deionized water and methyl alcohol $(35: 65, \mathrm{v} / \mathrm{v})$ at a constant flow rate of $1 \mathrm{~mL} \mathrm{~min}^{-1}$, LOD of $1.28 \mu \mathrm{g} \mathrm{L}^{-1}$, LOQ of $5.12 \mu \mathrm{g} \mathrm{L} \mathrm{L}^{-1}$.

Carbamazepine. Detection wavelength of $230 \mathrm{~nm}$, sample injection volume of $20 \mu \mathrm{L}$, mobile phase composed of deionized water and methyl alcohol $(10: 90, \mathrm{v} / \mathrm{v})$ at a constant flow rate of $1 \mathrm{~mL} \min ^{-1}$, LOD of $0.76 \mu \mathrm{g} \mathrm{L}^{-1}$, LOQ of $3.04 \mu \mathrm{g} \mathrm{L}^{-1}$.

Sulfamethoxazole. Detection wavelength of $270 \mathrm{~nm}$, sample injection volume of $20 \mu \mathrm{L}$, mobile phase composed of deionized water and acetonitrile $(80: 20, \mathrm{v} / \mathrm{v})$ at a constant flow rate of 1 $\mathrm{mL} \min ^{-1}$, LOD of $1.85 \mu \mathrm{g} \mathrm{L}^{-1}$, LOQ of $7.40 \mu \mathrm{g} \mathrm{L}^{-1}$.

Sulfadimidine. Detection wavelength of $270 \mathrm{~nm}$, sample injection volume of $20 \mu \mathrm{L}$, mobile phase composed of deionized water and acetonitrile $(80: 20, \mathrm{v} / \mathrm{v})$ at a constant flow rate of 1 $\mathrm{mL} \min ^{-1}$, LOD of $1.61 \mu \mathrm{g} \mathrm{L}^{-1}$, LOQ of $6.44 \mu \mathrm{g} \mathrm{L}^{-1}$.

Atenolol. Detection wavelength of $275 \mathrm{~nm}$, sample injection volume of $50 \mu \mathrm{L}$, mobile phase composed of deionized water and methyl alcohol $(70: 30, \mathrm{v} / \mathrm{v})$ at a constant flow rate of 1 $\mathrm{mL} \min ^{-1}$, LOD of $1.62 \mu \mathrm{g} \mathrm{L}^{-1}$, LOQ of $6.48 \mu \mathrm{g} \mathrm{L}^{-1}$.

Norfloxacin. Detection wavelengths of $278 \mathrm{~nm}$, sample injection volume of $50 \mu \mathrm{L}$, mobile phase composed of deionized water (buffered $0.025 \mathrm{~mol} \mathrm{~L}^{-1}$ phosphoric acid and adjusted $\mathrm{pH}$ to 3 by triethylamine) and acetonitrile $(87: 13, \mathrm{v} / \mathrm{v})$ at a constant flow rate of $1 \mathrm{~mL} \mathrm{~min}{ }^{-1}$, LOD of $1.10 \mu \mathrm{g} \mathrm{L}^{-1}$, LOQ of $4.40 \mu \mathrm{g} \mathrm{L}^{-1}$.

\section{Results and discussion}

\subsection{Surface charge property analysis}

The surface charge properties of the PEI-NF and PIP-NF membranes were further investigated using the zeta potential. The surface zeta potential of the PEI-NF and PIP-NF membranes are show in Fig. 1. The isoelectric point (IEP) of the PEI-NF and PIP-NF membranes were at a $\mathrm{pH}$ value of approximately 8.2 and 6.6, respectively. The surface zeta potential measurements indicate that the PEI-NF and PIP-NF membranes will present positive charges and negative charges, respectively, during filtration operation at neutral $\mathrm{pH}$.

\subsection{Adsorption kinetics of pharmaceuticals on NF membranes}

The adsorption experiments were carried out at 0.4 MPa and $25{ }^{\circ} \mathrm{C}$ with a neutral solution of $1000 \mu \mathrm{g} \mathrm{\textrm {L } ^ { - 1 }}$. Fig. 2(a) and 3(a) show the relation of permeate concentration of different pharmaceuticals with filtration time for the PEI-NF and PIP-NF membranes. The permeate concentration of pharmaceuticals was low at the initial stage of adsorption and then increased rapidly until the adsorption reached equilibrium as the filtration time continued. Both NF membranes attained the adsorption equilibrium within $30 \mathrm{~min}$. The volume of the feed solution is $2 \mathrm{~L}$. At the initial stage of adsorption, large concentration differences in the feed solution and membrane phase led to a rapid diffusion of pharmaceutical molecules from the bulk solution to the membrane surface. The adsorption equilibrium time of the six pharmaceuticals for both the PEI-NF membrane and PIP-NF membrane was short and close. This may be related to the hydrophilicity of pharmaceutical molecules. From Table 1 we can see that all the pharmaceuticals used in this study are hydrophilic $\left(\log k_{\text {ow }}<3\right),{ }^{31}$ so the adsorption properties of pharmaceuticals on membrane was weak. Fig. 2(b) and 3(b) show that the rejection rate of each pharmaceutical declined gradually until it reached equilibrium with the filtration time prolonging. After the pharmaceuticals reached adsorption equilibrium, the rejection rate of primidone, carbamazepine, sulfamethoxazole, atenolol, sulfadimidine and norfloxacin by the PEI-NF membrane was $86.5 \%$, $91.8 \%, 79.9 \%, 98.1 \%, 93.3 \%$ and $97.1 \%$, respectively. In addition, the rejection rate of primidone, carbamazepine, sulfamethoxazole, atenolol, sulfadimidine and norfloxacin for the PIPNF membrane was $82.2 \%, 85.4 \%, 91.5 \%, 79.1 \%, 87 \%$ and $93.3 \%$, respectively. The rejection of neutral molecules increased as the molecular weight increased. Steric hindrance played an important role in the rejection. The PEI-NF membrane is positively charged and the PIP-NF membrane is negatively charged in a neutral $\mathrm{pH}$ solution. For positively charged atenolol, the rejection by the PEI-NF membrane was higher than that by the PIP-NF membrane. In addition, the

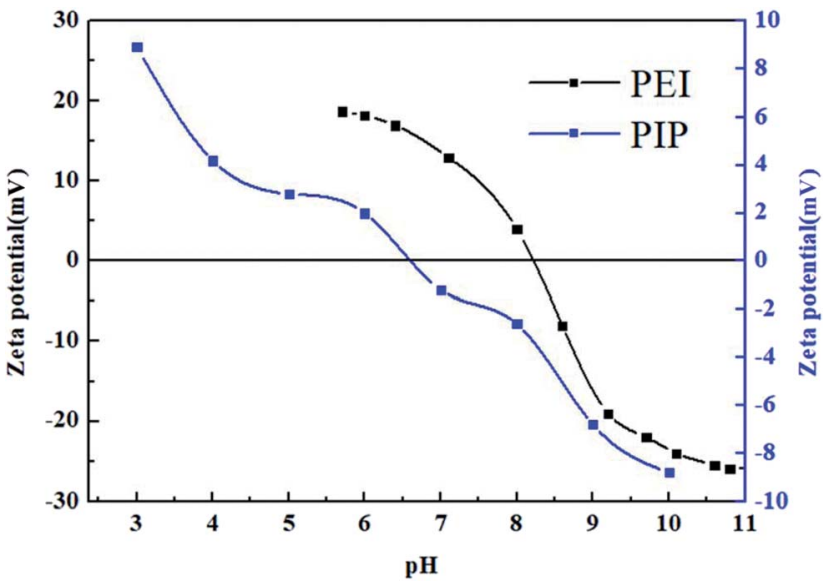

Fig. 1 Surface zeta potential of PEI-NF membrane and PIP-NF membrane with different $\mathrm{pH}$ values. 



Fig. 2 (a) Permeate concentration changes with a prolonged filtration time for PEI-NF membranes and (b) rejection and permeate flux of PPCPs as a function of filtration time for PEI-NF membranes $\left(25^{\circ} \mathrm{C}, \mathrm{pH}=7\right.$ and $\left.0.4 \mathrm{MPa}\right)$.

rejection of negatively charged sulfamethoxazole by the PEI-NF membrane was lower than that by the PIP-NF membrane. This was due to the electrostatic interaction between sulfamethoxazole and the membrane surface. The electrostatic repulsion between PIP-NF membrane and sulfamethoxazole resulted in a higher rejection rate. In addition, the PEI-NF membrane had electrostatic attraction to sulfamethoxazole, which lead to a relative lower rejection. ${ }^{32}$

\subsection{Stability test of NF membranes}

Fig. 4(a) and (b) show the permeate flux and rejection rate stability of carbamazepine with filtration time for the PEI-NF and PIP-NF membrane during 7 days operation. The results indicate that the PEI-NF and PIP-NF membranes exhibited good rejection stability. The PEI-NF and PIP-NF permeation flux were stable at $41 \mathrm{~L}\left(\mathrm{~m}^{2} \mathrm{~h}\right)^{-1}$ and $46 \mathrm{~L}\left(\mathrm{~m}^{2} \mathrm{~h}\right)^{-1}$, respectively. One of the factor which affect permeation flux is the hydrophilicity of the membranes. The contact angle of PEI-NF and PIP-NF membranes are $50.1^{\circ}$ and $71.1^{\circ}$, respectively (Table 1). Generally speaking, the better the hydrophilicity of the membrane was, the higher of the permeation flux would be..$^{20,21}$ Because it would be easier for the water molecules penetrate through the membrane. However, the flux of the membranes also be affected by the material of the membranes, the roughness of the membrane surface etc. From Fig. 5 we can see the surface of PIPNF membranes is rougher than that of PEI-NF membrane. Combining the hydrophilicity and the surface roughness, PIPNF shows relative higher permeation flux. The rejection rate fluctuated slightly, at approximately $91.8 \%$ and $85.6 \%$ for PEI$\mathrm{NF}$ and PIP-NF, respectively, under the experimental conditions.

\subsection{Effect of operation conditions on nanofiltration performance}

3.4.1. Effect of pharmaceutical concentration. Fig. 6 shows the influence of feed concentration of the pharmaceuticals on the permeate flux and rejection rates for both the PEI-NF membrane and PIP-NF membranes at the pressure of 0.4 MPa. The permeate flux of the PEI-NF membrane stabilized at approximately $40 \mathrm{~L}\left(\mathrm{~m}^{2} \mathrm{~h}\right)^{-1}$, and the flux of the PIP-NF membrane stabilized at $45 \mathrm{~L}\left(\mathrm{~m}^{2} \mathrm{~h}\right)^{-1}$. When the concentration of pharmaceuticals was $1000 \mu \mathrm{g} \mathrm{L}^{-1}$, the rejection rates for
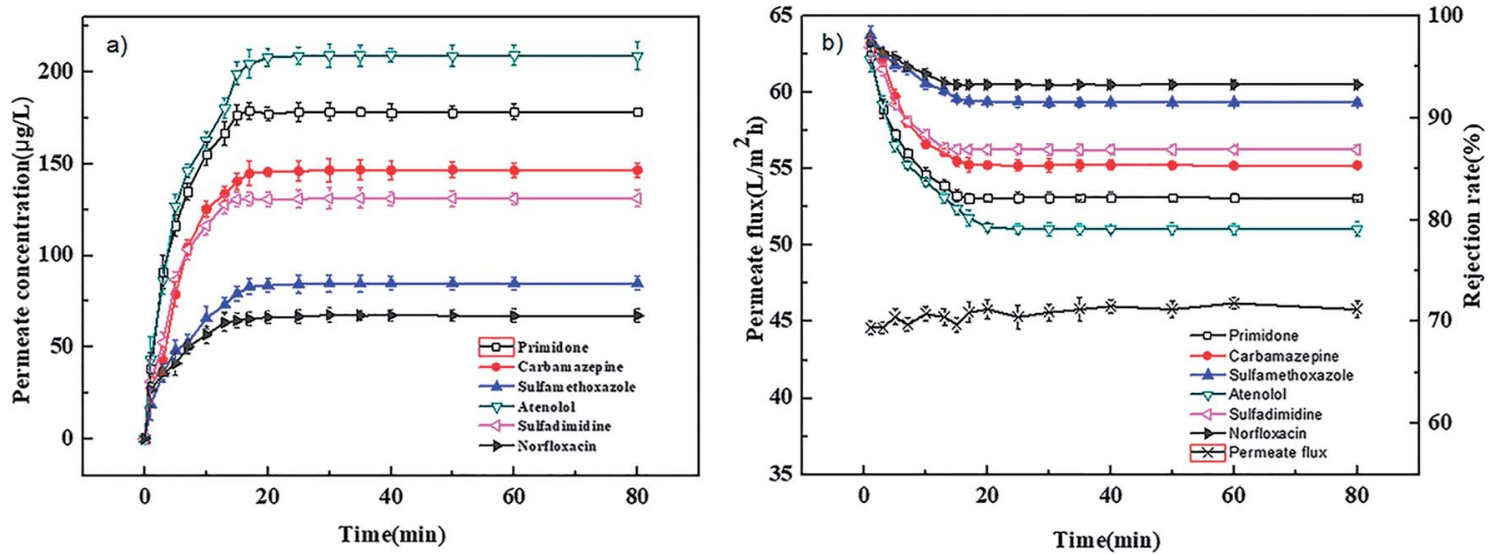

Fig. 3 (a) Permeate concentration changes with a prolonged filtration time for PIP-NF membranes and (b) rejection and permeate flux of PPCPs as a function of filtration time for PIP-NF membranes $\left(25^{\circ} \mathrm{C}, \mathrm{pH}=7\right.$ and $\left.0.4 \mathrm{MPa}\right)$. 

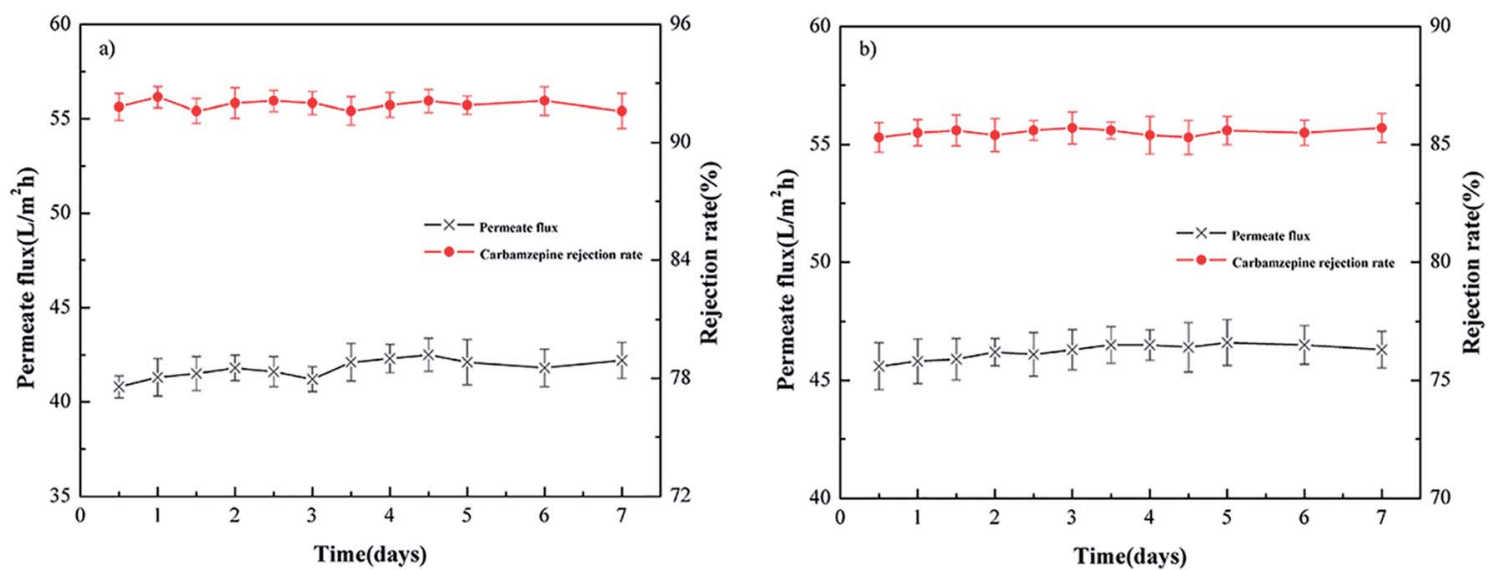

Fig. 4 Rejection stability of different NF membranes. (a) PEI-NF membrane and (b) PIP-NF membrane performance $\left(25^{\circ} \mathrm{C}, \mathrm{pH}=7\right.$ and $0.4 \mathrm{MPa}$ ).

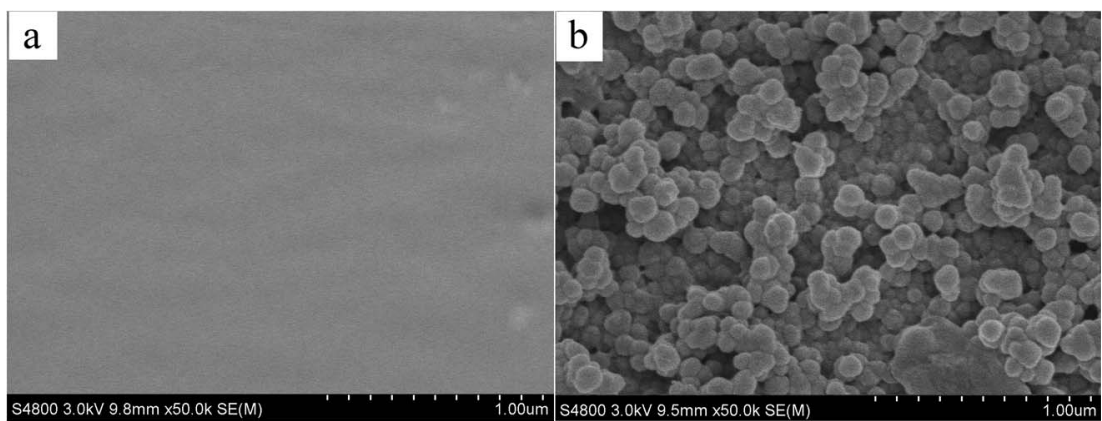

Fig. 5 Surface morphology of (a) PEI-NF membrane and (b) PIP-NF membrane.
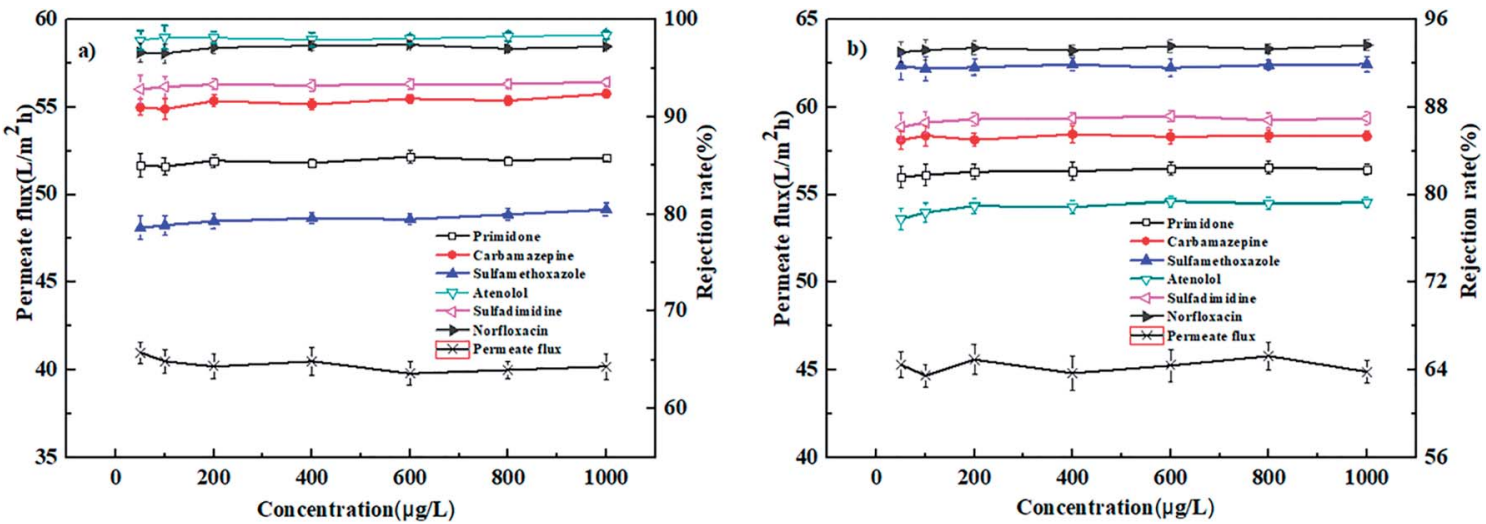

Fig. 6 Effect of feed concentration on the flux and rejection rates of PPCPs for (a) PEI-NF membrane and (b) PIP-NF membrane $\left(25^{\circ} \mathrm{C}, \mathrm{pH}=7\right.$ and $0.4 \mathrm{MPa}$ )

both the PEI-NF membrane and PIP-NF membrane have no significant changes compared to the concentration of $50 \mu \mathrm{g} \mathrm{L}^{-1}$. So, the whole irregular trend of rejection rate is not obvious in Fig. 6(a) and (b). This illustrated that the relative low concentration of pharmaceutical molecules had little effect on the permeate flux and rejection rate for the two charged NF membranes,$^{33}$ which is attributed to the fact that the distribution coefficient of the target pollutant between the host solution and the membrane is constant. The PEI-NF membrane and PIPNF membrane had a stable permeate flux and rejection rate when the feed concentration changed from $50 \mu \mathrm{g} \mathrm{L} \mathrm{L}^{-1}$ to $1000 \mu \mathrm{g}$ $\mathrm{L}^{-1}$. The pharmaceutical concentration in different environmental waters is different. For surface water and groundwater, the pharmaceutical concentration is in the $n g \mathrm{~L}^{-1}$ to $\mu \mathrm{g} \mathrm{L}^{-1}$ range. However, the concentration of pharmaceuticals in wastewater and landfill leachate is relatively higher and may 

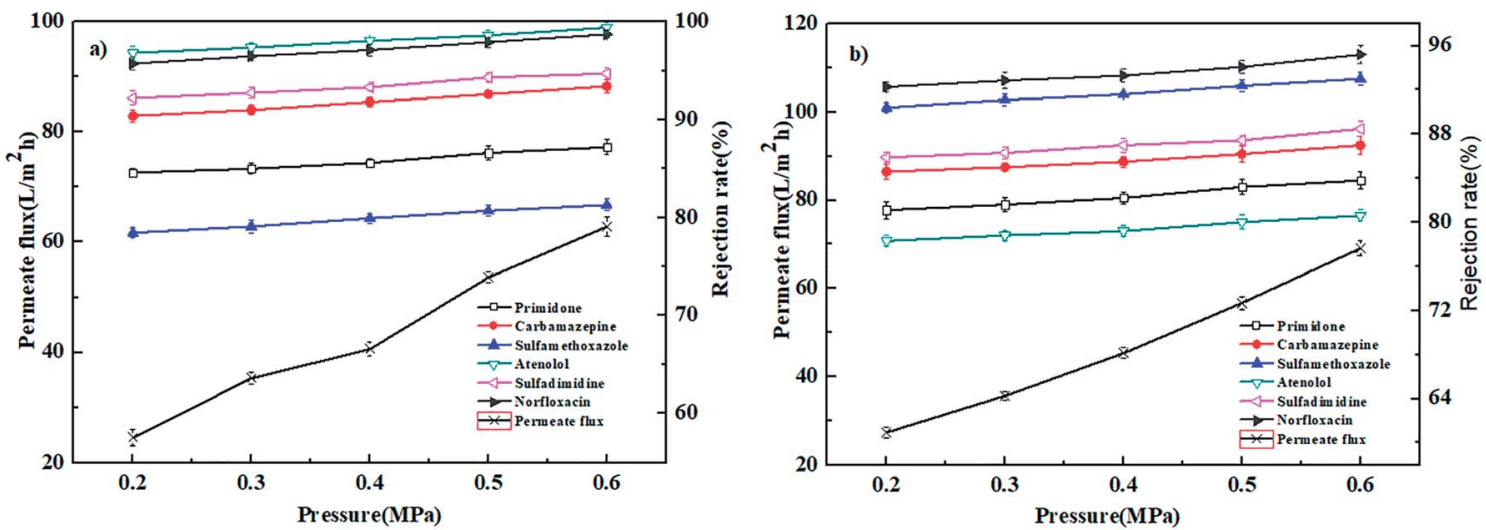

Fig. 7 Effect of operation pressure on the permeate flux and rejection rates of PPCPs for (a) PEI-NF membrane and (b) PIP-NF membrane (25 ${ }^{\circ} \mathrm{C}$, $0.4 \mathrm{MPa}$ ).

reach to the $\mu \mathrm{g} \mathrm{L}^{-1}$ to $\mathrm{mg} \mathrm{L}^{-1}$ range. For ease of characterization, the feed concentration of $1000 \mu \mathrm{g} \mathrm{L}{ }^{-1}$ was chosen in this study.

3.4.2. Effect of operation pressure on NF performance. Fig. 7(a) and (b) show the effects of operation pressure on the permeate flux and pharmaceutical rejection for both NF membranes. When the pressure rose from 0.2 MPa to 0.6 MPa, the flux of the PEI-NF membrane rose from $24.5 \mathrm{~L}\left(\mathrm{~m}^{2} \mathrm{~h}\right)^{-1}$ to $62.8 \mathrm{~L}\left(\mathrm{~m}^{2} \mathrm{~h}\right)^{-1}$ and the flux of the PIP-NF membrane rose from $27.3 \mathrm{~L}\left(\mathrm{~m}^{2} \mathrm{~h}\right)^{-1}$ to $69.1 \mathrm{~L}\left(\mathrm{~m}^{2} \mathrm{~h}\right)^{-1}$. The permeate flux of the NF membranes increased linearly as the pressure increased. NF is a pressure-driven membrane process for separation. According to the water flux equation based on the dissolution-diffusion model: $J_{\mathrm{w}}=-A(\Delta P-\Delta \pi)$, where $J_{\mathrm{w}}$ is the water flux, $A$ is the water permeability constant, $\Delta P$ is the hydraulic pressure difference across the membrane, and $\Delta \pi$ is the osmotic pressure differential across the membrane, the membrane flux increases with pressure increasing. Fig. 7(a) shows that the rejection rates of the six pharmaceuticals by the PEI-NF membrane rose slowly with increasing operation pressure, as did the rejection rates of the PIP-NF membrane. This can be explained by the salt flux equation based on the dissolutiondiffusion model: $J_{\mathrm{s}}=-B \Delta C_{\mathrm{s}}$, where $J_{\mathrm{s}}$ is the solute flux, $B$ is the solute permeability constant, and $\Delta C_{\mathrm{s}}$ is the solute concentration differential across the membrane. The solute flux is the function of the solute concentration differential across the membrane and has no direct relationship with pressure. The volume of water through the membrane increased and the pharmaceutical molecules permeate through the membrane was mostly unchanged with increasing pressure. Additionally, the increased pressure may compact the membrane structure, which may hinder the ability of the pharmaceutical molecules to pass though the membranes. ${ }^{34}$ Fig. 8 shows the cross-section (Fig. 8a-d) and the surface morphology (Fig. 8e-h) images of the $\mathrm{NF}$ membranes after they were used under 0.2 MPa and 0.6 MPa. As it can be seen from Fig. 8a-d, the thickness of the selective layer for PIP-NF and PEI-NF operated at 0.6 MPa are thinner than that of operated at $0.2 \mathrm{MPa}$. The results indicated that the selective layer of the NF membranes would become denser with the increase of operation pressure. As a result, the pharmaceuticals rejection rates increased. During the operation process, some pharmaceutical molecules were deposited onto the inner surfaces of NF membranes which lead the membranes were fouled. The results indicated that PIP-NF membranes is fouled more serious than that of PEI-NF membranes due to PEI shows better hydrophilicity than that of PIP-NF membranes (Table 1). And it was found that NF membranes operated at 0.2 MPa was fouled more seriously than that of operated at 0.6 MPa (Fig. 8e-h). It is because the NF membrane was compressed, which make the membrane surface become smooth under relative higher pressure. On the other hand, the deposited pharmaceutical molecules could be washed away easier by the cross-flow force at $0.6 \mathrm{MPa}$ than that of at $0.2 \mathrm{MPa}$. However, the concentration polarization caused by the increasing pressure can result in the decrease of rejection. Combining these two effects, the pharmaceutical rejection rates by the two NF membranes increased slowly.

In conclusion, the PEI-NF and PIP-NF membrane showed relatively stable rejection behavior when the operation pressure rose from 0.2 MPa to 0.6 MPa. Considering the energy consumption and economic life of the membrane, 0.4 MPa was chosen in the following NF processes.

3.4.3. Effect of temperature on NF performance. The effect of temperature $\left(25-45{ }^{\circ} \mathrm{C}\right)$ on the permeate flux and rejection rates for the PEI-NF and PIP-NF membranes were also investigated. Fig. 9 shows that the increase of permeate flux for both the PEI-NF and PIP-NF membrane was accompanied with a decrease of rejection rates when the operation temperature increased. The flux of the PEI-NF membrane rose from $40.6 \mathrm{~L}$ $\left(\mathrm{m}^{2} \mathrm{~h}\right)^{-1}$ to $59.2 \mathrm{~L}\left(\mathrm{~m}^{2} \mathrm{~h}\right)^{-1}$, and the flux of the PIP-NF membrane rose from $45.2 \mathrm{~L}\left(\mathrm{~m}^{2} \mathrm{~h}\right)^{-1}$ to $66.3 \mathrm{~L}\left(\mathrm{~m}^{2} \mathrm{~h}\right)^{-1}$. This increase was caused by the increase of the membranes' effective pore diameter due to the temperature increase..$^{35,36}$ In general, the adsorption of water on the pore walls may reduce the effective pore diameter of the membranes. ${ }^{37}$ With rising temperature, the adsorption water layer would be thinner and the pore diameter would be larger. Some research results show that the actual pore size of NF membranes is not affected by 


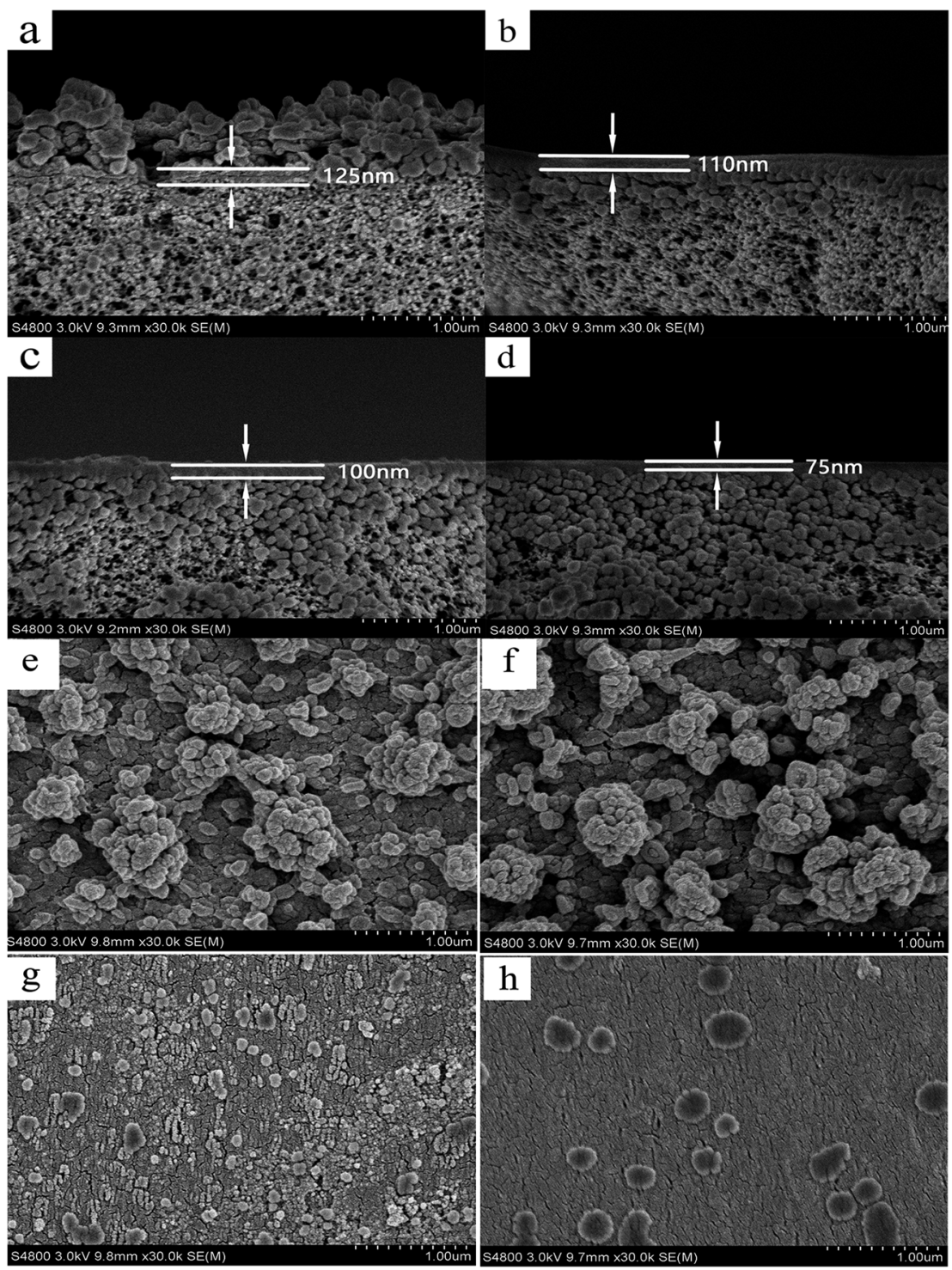

Fig. 8 Cross-section image under different operation pressure. (a) PIP-NF under 0.2 MPa, (b) PIP-NF under 0.6 MPa, (c) PEI-NF under 0.2 MPa, (d) PEI-NF under 0.6 MPa; surface morphology under different operation pressure. (e) PIP-NF under 0.2 MPa, (f) PIP-NF under 0.6 MPa, (g) PEI-NF under 0.2 MPa, (h) PEI-NF under 0.6 MPa.

temperature due to the effective pore diameter being larger for a thinner adsorption water layer. ${ }^{37}$ On the other hand, the bulk water viscosity and the intrapore viscosity may reduce with the rising temperature. Both effects would endow the NF membrane with a relatively higher flux. It can be seen from Fig. 9(a) and (b) that all the rejection rates of the pharmaceuticals for both NF membranes decreased to some extent with increasing temperature. The pharmaceutical permeation process is an activated process. The thermal energy supplied by relative high temperature could increase the diffusivity of the pharmaceutical molecules which help the molecules to overcome the pore wall frictional forces, making the pharmaceutical molecules pass through the NF membrane more easily. ${ }^{38}$ However, the rejection rates of the norfloxacin with higher MW decreased slightly. ${ }^{39,40}$ The decline of the pharmaceutical rejection rate was different for the PEI-NF and PIP-NF membrane. This phenomenon may be attributed to the intrapore viscosity of the pharmaceutical molecules varying with the membrane structure and pharmaceutical conformation.

3.4.4. Effect of $\mathbf{p H}$ on $\mathrm{NF}$ membrane performance. Fig. 10 shows the influence of $\mathrm{pH}$ value on permeate flux and pharmaceutical rejection by the NF membranes. In this study, $\mathrm{NaOH} / \mathrm{HCl}$ solution was used to adjust the feed solution $\mathrm{pH}$ from 3 to 9. Fig. 10(a) shows that the permeate flux of the PEI-NF membrane increased first and then decreased after reaching the maximum flux of $41 \mathrm{~L}\left(\mathrm{~m}^{2} \mathrm{~h}\right)^{-1}$ at $\mathrm{pH}=8$. For the PIP-NF membrane, the permeate flux also increased first and then decreased with $\mathrm{pH}$ increasing, reaching a maximum of $45 \mathrm{~L}\left(\mathrm{~m}^{2}\right.$ $\mathrm{h})^{-1}$ at $\mathrm{pH}=7$. The results may be due to the effect of varying $\mathrm{pH}$ value on the pore size of the membrane. ${ }^{41}$ The IEP value of the PEI-NF membrane is 8.2, and the IEP value of the PIP-NF membrane is approximately 6.6. When the $\mathrm{pH}$ value is higher 

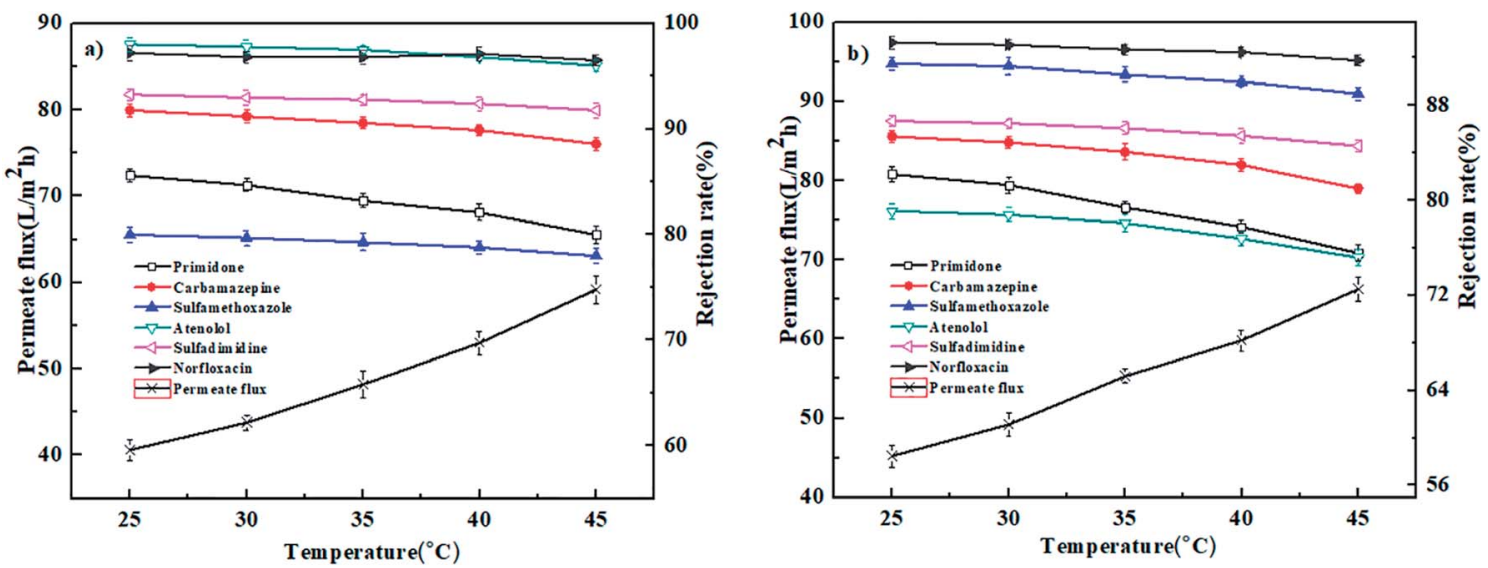

Fig. 9 Effect of temperature on the permeate flux and rejection rates of PPCPs for (a) PEI-NF membrane and (b) PIP-NF membrane ( $p H=7,0.4$ $\mathrm{MPa})$.

or lower than the IEP, the $\mathrm{H}^{+} / \mathrm{OH}^{-}$in the solution and the co-ion on the membrane surface are mutually exclusive, which causes the membrane to swell and reduce the membrane pore size. When the $\mathrm{pH}$ value is similar with to the IEP value of the membrane, the membrane surface presents no charge and the pore size is the largest. Therefore, the permeate flux of the two $\mathrm{NF}$ membranes achieved the maximum permeate flux at a $\mathrm{pH}$ near their IEP value. ${ }^{42}$

As shown in Fig. 10(a), the rejection rates of primidone, carbamazepine, sulfamethoxazole, sulfadimidine and norfloxacin by the PEI-NF membrane first decreased and then increased with increasing $\mathrm{pH}$, reaching its minimum at approximately $\mathrm{pH}=8$. For primidone and carbamazepine, which are neutrally charged at the experimental $\mathrm{pH}$, the retention is governed by steric hindrance between the membrane pore size and different molecules. The results indicated that the change of rejection rate for primidone and carbamazepine are not very obviously compared to other pharmaceuticals. Sulfamethoxazol $\left(\mathrm{p} K_{\mathrm{a}}=1.6,5.7\right)$ and sulfadimidine $\left(\mathrm{p} K_{\mathrm{a}}=2.65,7.65\right)$ transformed from a neutral species to negatively charged as the $\mathrm{pH}$ increased from 3 to 9 . The rejection rate of sulfamethoxazole decreased quickly when the $\mathrm{pH}$ increased from 6 to 8 . At the $\mathrm{pH}$ range, sulfamethoxazole was negatively charged and was easily transported to the positively charged membrane surface due to electrostatic attraction. When $\mathrm{pH}$ increased from 8 to 9 , the positively charged PEI-NF membrane presented a negative charge, and the electrostatic repulsion between the pharmaceutical molecules and membrane surface resulted in the relative higher rejection rate. The positively charged norfloxacin turned to a slightly negative charge as the $\mathrm{pH}$ value increased. When the $\mathrm{pH}$ increased from 3 to 8 , the electrostatic repulsion was weakened between norfloxacin and membrane surface, which led to a slight decrease in the rejection rate. From Fig. 10(a), we can see that the rejection rate of atenolol decreased with the increasing $\mathrm{pH}$. Atenolol is positively charged at the $\mathrm{pH}$ range of the experiment. The rejection decrease can be attributed to a decrease in the electrostatic repulsion and increase in the electrostatic attraction between atenolol and the membrane surface as the $\mathrm{pH}$ increased.

Fig. 10(b) shows the effect of $\mathrm{pH}$ on pharmaceutical rejection for the PIP-NF membrane. The rejection rates of primidone, carbamazepine, sulfadimidine and norfloxacin increased when the $\mathrm{pH}$ increased from 3 to 7 and decreased when the $\mathrm{pH}$ increasing from 7 to 9 . The membrane pore size is largest at the
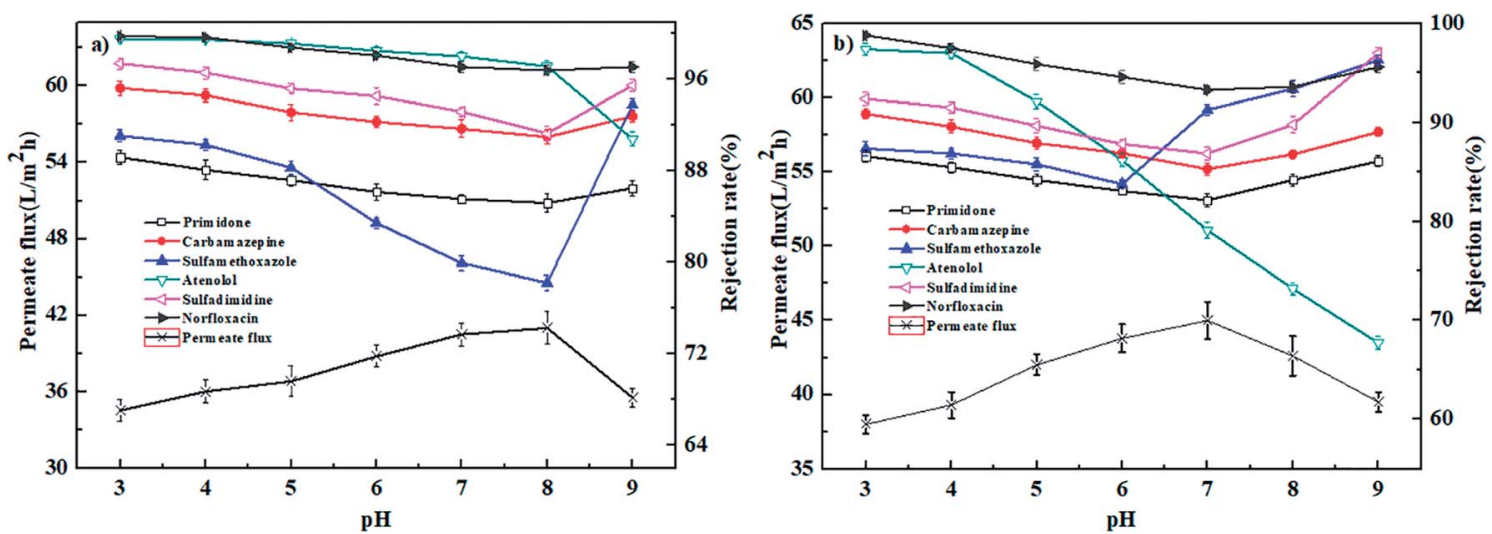

Fig. 10 Effect of $\mathrm{pH}$ value on the permeate flux and rejection rates of PPCPs for (a) PEI-NF membrane and (b) PIP-NF membrane (25 ${ }^{\circ} \mathrm{C}, 0.4$ $\mathrm{MPa})$. 

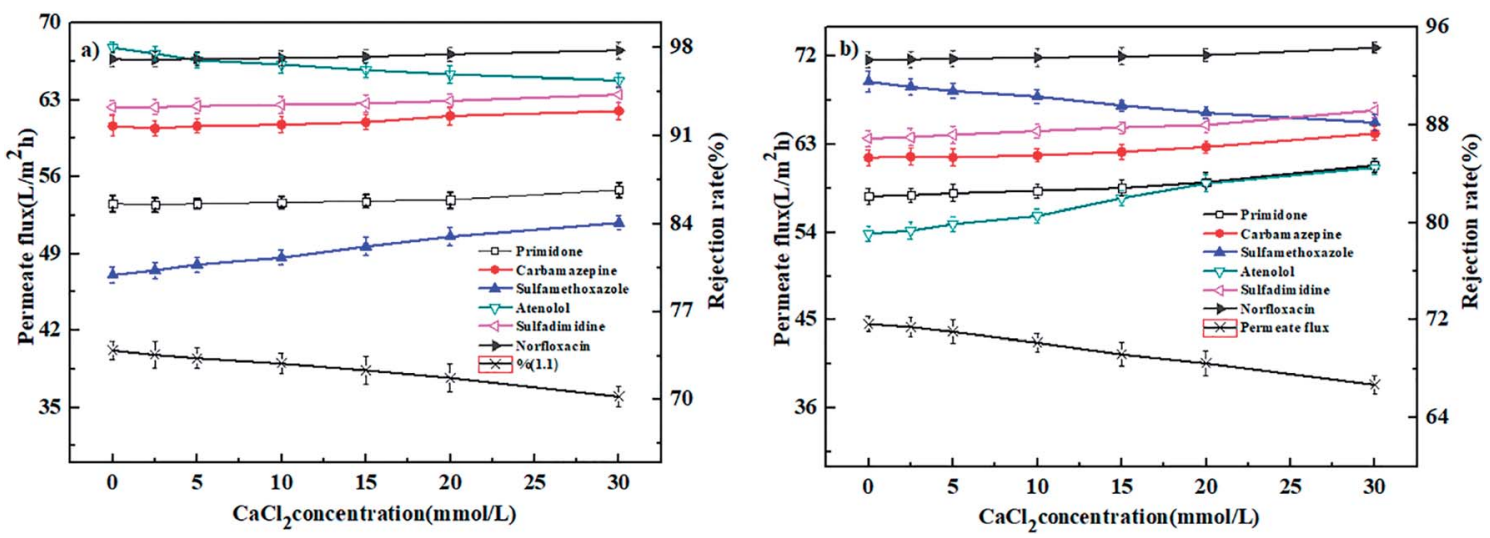

Fig. 11 Effect of ionic strength on the permeate flux and rejection rates of PPCPs for (a) PEI-NF membrane and (b) PIP-NF membrane (25 ${ }^{\circ} \mathrm{C}$, $\mathrm{pH}$ $=7$ and $0.4 \mathrm{MPa})$.

$\mathrm{pH}$ of the IEP (the IEP of the PIP-NF membrane is 6.6). For uncharged pharmaceutical molecules, the rejection rate is controlled by steric hindrance. When $\mathrm{pH}$ increased from 8 to 9 , a more negatively charged sulfadimidine was generated in the solution. The strengthened electrostatic repulsion between sulfadimidine and the PIP-NF membrane surface led the NF membrane to show a relatively higher rejection rate. For norfloxacin, when the $\mathrm{pH}$ decreased below its $\mathrm{p} K_{\mathrm{a}}$ value of 6.34 or increased above 8.75 , the electrostatic repulsion between norfloxacin and the membrane surface was enhanced, which resulted in a higher rejection rate. The rejection rate of sulfamethoxazole for PIP-NF decreased first and then increased with an increase in the solution $\mathrm{pH}$, reaching the minimum at $\mathrm{pH}=$ 6. Sulfamethoxazole $\left(\mathrm{p} K_{\mathrm{a}}=1.6,5.7\right)$ transformed from uncharged to negatively charged as the $\mathrm{pH}$ increased from 3 to 9. When the $\mathrm{pH}=6$, the negatively charged sulfamethoxazole was easily adsorbed onto the positively charged membrane surface because of electrostatic adsorption. ${ }^{43}$ When the solution $\mathrm{pH}$ increased to above 6 , the negatively charged sulfamethoxazole molecules were excluded by the negative charges on the PIP-NF membrane surface, which resulted in a higher rejection rate by the NF membrane. The rejection rate of atenolol for the PIP-NF membrane decreased quickly because the electrostatic repulsion between atenolol and the membrane surface was eliminated with the increasing solution $\mathrm{pH}$.

When the solution $\mathrm{pH}$ was 3 to 5 , the rejection rate of the uncharged carbamazepine was higher than the uncharged sulfamethoxazole for both the PEI-NF and PIP-NF membranes (Fig. 10), even though sulfamethoxazole has the higher molecular weight. Similar results were also reported in ref. 17 and 44 . This phenomenon can be explained by the effect of the dipole moments of molecules with similar molecular weights. The molecules in the feed solution move to the membrane surface along a certain direction due to the attraction between polar molecules and charged groups in the membrane. The carbamazepine with a lower dipole moment of $3.6 \mathrm{D}$ exhibits a relatively larger three-dimensional structure than that of sulfamethoxazole with a higher dipole, which gives carbamazepine a higher rejection rate. ${ }^{45,46}$
3.4.5. Effect of ionic strength on NF performance. Fig. 11(a) and (b) show the effect of ionic strength on the permeate flux and pharmaceutical rejection by the PEI-NF membrane and PIPNF membrane. Different concentrations of $\mathrm{CaCl}_{2}$ were added to change the ionic strength of the solution. Both the permeate flux of the PEI-NF membrane and PIP-NF membrane were decreased with increasing $\mathrm{CaCl}_{2}$ concentration. ${ }^{47,48}$ In addition, the rejection rates of the uncharged pharmaceuticals increased slightly for the two NF membranes. This is due to the higher salt concentration in the solution, which increased the membrane compactness reduced the porosity and pore size, resulting in a lower flux and higher rejection rate for the uncharged pharmaceuticals. Another explanation is that higher salt concentration increased the concentration polarization, which restrained the permeate flux. For PEI-NF membranes, the rejection rate of the negatively charged sulfamethoxazole increased and the rejection rate of positively charged atenolol decreased. In contrast, the rejection rate of sulfamethoxazole decreased and the rejection rate of atenolol increased for the PIP-NF membrane. For the PEI-NF membrane, the $\mathrm{Cl}^{-}$in the solution might shield the positive charge on the membrane surface and lead to a decrease of electrostatic repulsion between the membrane surface and positively charged atenolol. Additionally, the electrostatic attraction between the negatively charged sulfamethoxazole and membrane surface would be weaker. The negative charge on the PIP-NF membrane surface was shielded by the addition of $\mathrm{Ca}^{2+}$, which decreases the electrostatic interactions between charged pharmaceuticals and the membrane surface. ${ }^{49}$

\section{Conclusion}

The results indicated that both the PEI-NF and PIP-NF membrane showed a very fast adsorption rate at the initial adsorption stage and then reached adsorption equilibrium. The saturation adsorption time of the different pharmaceutical molecules on the two membrane surfaces did not show obvious differences as a result of the molecular weight, charge and hydrophilicity of the pharmaceutical molecules. The steric 
hindrance effect played a dominant role for the NF membrane removal of neutral pharmaceutical molecules. For the charged pharmaceutical molecules, the removal behavior of the two different charged hollow fiber NF membranes was determined by the collaborative effect of steric hindrance and electrostatic repulsion. Generally, the rejection rate of the charged NF membrane for the same kind of charged pharmaceutical molecules is higher than the oppositely charged pharmaceutical molecules.

The effect of feed concentration, operation pressure, and temperature on the rejection rates of pharmaceuticals was not very obvious. With the change of $\mathrm{pH}$ value and ionic strength, the rejection rates of the pharmaceutical molecules by the two NF membranes changed noticeably. The results were attributed to the pharmaceuticals' chemical properties, the membrane pore size and the surface charge. The interaction between the pharmaceutical molecules and membrane surface changed due to the changes of operation parameters. This study suggests the impressive potential for charged NF membranes for applications in the field of trace pollutants removal from drinking water sources.

\section{Conflicts of interest}

There are no conflicts to declare.

\section{Acknowledgements}

The authors gratefully acknowledge financial support from the Natural Science Foundation of Zhejiang Province (Grant No. LY14B070007, LY13H280009) and MOE Key Laboratory of Macromolecular Synthesis and Functionalization, Zhejiang University (2017MSF05). The authors also sincerely thank the Open Foundation from the Top Key Discipline of Environmental Science and Engineering, Zhejiang University of Technology (Grant No. 20150314).

\section{References}

1 Q. W. Bu, B. Wang, J. Huang, S. B. Deng and G. Yu, Pharmaceuticals and personal care products in the aquatic environment in China: a review, J. Hazard. Mater., 2013, 262, 189-211.

2 S. Suárez, M. Carballa, F. Omil and J. M. Lema, How are pharmaceutical and personal care products (PPCPs) removed from urban wastewaters?, Rev. Environ. Sci. Bio/ Technol., 2008, 7, 125-138.

3 M. F. Rahman, E. K. Yanful and S. Y. Jasim, Endocrine disrupting compounds (EDCs) and pharmaceuticals and personal care products (PPCPs) in the aquatic environment: implications for the drinking water industry and global environmental health, J. Water Health, 2009, 7, 224-243.

4 D. Barcelo and M. Petrovic, Pharmaceuticals and personal care products (PPCPs) in the environment, Anal. Bioanal. Chem., 2007, 387, 1141-1142.
5 J. B. Ellis, Pharmaceutical and personal care products (PPCPs) in urban receiving waters, Environ. Pollut., 2006, 144, 184-189.

6 C. G. Daughton and T. A. Ternes, Pharmaceuticals and personal care products in the environment: agents of subtle change?, Environ. Health Perspect., 1999, 107, 907-938.

7 S. A. Snyder, P. Westerhoff, Y. Yoon and D. L. Sedlak, Pharmaceuticals, personal care products, and endocrine disruptors in water: implications for the water industry, Environ. Eng. Sci., 2003, 20, 449-469.

8 Q. Sun, Y. Li, M. Y. Li, M. Ashfaq, M. Lv, H. J. Wang, A. Y. Hu and C. P. Yu, PPCPs in Jiulong River estuary (China): spatiotemporal distributions, fate, and their use as chemical markers of wastewater, Chemosphere, 2016, 150, 596-604.

9 J. Roberts, A. Kumar, J. Du, C. Hepplewhite, D. J. Ellis, A. G. Christy and S. G. Beavis, Pharmaceuticals and personal care products (PPCPs) in Australia's largest inland sewage treatment plant, and its contribution to a major Australian river during high and low flow, Sci. Total Environ., 2016, 541, 1625-1637.

10 E. N. Evgenidou, I. K. Konstantinou and D. A. Lambropoulou, Occurrence and removal of transformation products of PPCPs and illicit drugs in wastewaters: a review, Sci. Total Environ., 2015, 505, 905-926.

11 X. Z. Peng, K. Zhang, C. M. Tang, Q. X. Huang, Y. Y. Yu and J. L. Cui, Distribution pattern, behavior, and fate of antibacterials in urban aquatic environments in South China, J. Environ. Monit., 2011, 13, 446-454.

12 C. G. Daughton, Non-regulated water contaminants: emerging research, Environ Impact Assess Rev, 2004, 24, 711-732.

13 T. Brodin, J. Fick, M. Jonsson and J. Klaminder, Dilute Concentrations of a Psychiatric Drug Alter Behavior of Fish From Natural Populations, Science, 2013, 339, 814-815.

14 D. E. Conners, E. D. Rogers, K. L. Armbrust, J. W. Kwon and M. C. Black, Growth And Development Of Tadpoles (Xenopus Laevis) Exposed To Selective Serotonin Reuptake Inhibitors, Fluoxetine And Sertraline, Throughout Metamorphosis, Environ. Toxicol. Chem., 2009, 28, 26712676.

15 D. M. Oggier, C. I. Weisbrod, A. M. Stoller, A. K. Zenker and K. Fent, Effects of Diazepam on Gene Expression and Link to Physiological Effects in Different Life Stages in Zebrafish Danio rerio, Environ. Sci. Technol., 2010, 44, 7685-7691.

16 X. Z. Wei, X. Kong, S. X. Wang, H. Xiang, J. D. Wang and J. Y. Chen, Removal of Heavy Metals from Electroplating Wastewater by Thin-Film Composite Nanofiltration Hollow-Fiber Membranes, Ind. Eng. Chem. Res., 2013, 52, 17583-17590.

17 C. H. Gong, H. O. Huang and Q. Yu, Integrated electrocoagulation and membrane filtration for PAH removal from realistic industrial wastewater: effectiveness and mechanisms, RSC Adv., 2017, 7, 52366-52374.

18 J. A. Park, J. K. Kang and S. C. Lee, Electrospun poly(acrylic acid)/poly(vinyl alcohol) nanofibrous adsorbents for $\mathrm{Cu}(\mathrm{II})$ 
removal from industrial plating wastewater, $R S C A d v ., 2017$, 7, 18075-18084.

19 X. Shen, T. D. Xie and J. A. Wang, An anti-fouling poly(vinylidene fluoride) hybrid membrane blended with functionalized $\mathrm{ZrO}_{2}$ nanoparticles for efficient oil/water separation, RSC Adv., 2017, 7, 5262-5271.

20 X. Z. Wei, X. Kong, C. T. Sun and J. Y. Chen, Characterization and application of a thin-film composite nanofiltration hollow fiber membrane for dye desalination and concentration, Chem. Eng. J., 2013, 223, 172-182.

21 X. Z. Wei, S. X. Wang and Y. Y. Shi, Characterization of a positively charged composite nanofiltration hollow fiber membrane prepared by a simplified process, Desalination, 2014, 350, 44-52.

22 Y. F. Song, B. W. Su, X. L. Gao and C. J. Gao, The performance of polyamide nanofiltration membrane for long-term operation in an integrated membrane seawater pretreatment system, Desalination, 2012, 296, 30-36.

23 S. A. Snyder, S. Adham, A. M. Redding, F. S. Cannon, J. DeCarolis, J. Oppenheimer, E. C. Wert and Y. Yoon, Role of membranes and activated carbon in the removal of endocrine disruptors and pharmaceuticals, Desalination, 2007, 202, 156-181.

24 Y. Yoon, P. Westerhoff, S. A. Snyder and E. C. Wert, Nanofiltration and ultrafiltration of endocrine disrupting compounds, pharmaceuticals and personal care products, J. Membr. Sci., 2006, 270, 88-100.

25 Z. L. Can, P. S. Shi and Y. L. Fu, Treatment of highly concentrated wastewater containing multiple synthetic dyes by a combined process of coagulation/flocculation and nanofiltration, J. Membr. Sci., 2014, 469, 306-315.

26 K. O. Yee, Y. L. Fu and P. S. Shi, Nanofiltration hollow fiber membranes for textile wastewater treatment: lab-scale and pilot-scale studies, Chem. Eng. Sci., 2014, 114, 51-57.

27 L. Setiawan, L. Shi and R. Wang, Dual layer composite nanofiltration hollow fiber membranes for low-pressure water softening, Polymer, 2014, 55, 1367-1374.

28 L. Yu and Y. T. Zhang, High flux, positively charged loose nanofiltration membrane by blending with poly (ionic liquid) brushes grafted silica spheres, J. Hazard. Mater., 2015, 287, 373-383.

29 J. Y. Zhu and M. M. Tian, Fabrication of a novel "loose" nanofiltration membrane by facile blending with Chitosan-Montmorillonite nanosheets for dyes purification, Chem. Eng. J., 2015, 265, 184-193.

$30 \mathrm{Z}$. Wang, Distribution and attenuation of typical pharmaceuticals, in Shenzhen river watershed and control technology, Tsinghua University, Beijing, China, 2015.

31 S. Seethapathy, T. Górecki and X. J. Li, Passive sampling in environmental analysis, J. Chromatogr. A, 2008, 1184, 234253.

32 A. R. D. Verliefde, S. G. Heijman, E. R. Cornelissen, G. Amy, B. Van der Bruggen and J. C. van Dijk, Influence of electrostatic interactions on the rejection with $\mathrm{NF}$ and assessment of the removal efficiency during NF/GAC treatment of pharmaceutically active compounds in surface water, Water Res., 2007, 41, 3227-3240.
33 B. Van der Bruggen, J. Schaep, W. Maes, D. Wilms and C. Vandecasteele, Nanofiltration as a treatment method for the removal of pesticides from ground waters, Desalination, 1998, 117, 139-147.

34 E. E. Chang, C. H. Liang, C. P. Huang and P. C. Chiang, A simplified method for elucidating the effect of size exclusion on nanofiltration membranes, Sep. Purif. Technol., 2012, 85, 1-7.

35 J. M. Arsuaga, M. J. Lopez-Munoz, J. Aguado and A. Sotto, Temperature, $\mathrm{pH}$ and concentration effects on retention and transport of organic pollutants across thin-film composite nanofiltration membranes, Desalination, 2008, 221, 253-258.

36 N. Ben Amar, H. Saidani, J. Palmeri and A. Deratani, Effect of temperature on the rejection of neutral and charged solutes by Desal 5 DK nanofiltration membrane, Desalination, 2009, 246, 294-303.

37 N. Ben Amar, H. Saidani, A. Deratani and J. Palmeri, Effect of temperature on the transport of water and neutral solutes across nanofiltration membranes, Langmuir, 2007, 23, 2937-2952.

38 T. Tsuru, T. Izumi and T. Yoshioka, Temperature effect on transport performance by inorganic nanofiltration membrane, AIChE J., 2000, 46, 565-574.

39 A. K. Goulas, P. G. Kapasakalidis, H. R. Sinclair, R. A. Rastall and A. S. Grandison, Purification of oligosaccharides by nanofiltration, J. Membr. Sci., 2002, 209, 321-335.

40 D. Majumdar, T. Zhu and G. J. Boons, Synthesis of oligosaccharides on soluble high-molecular-weight branched polymers in combination with purification by nanofiltration, Org. Lett., 2003, 5, 3591-3594.

41 A. E. Childress and M. Elimelech, Effect of solution chemistry on the surface charge of polymeric reverse osmosis and nanofiltration membranes, J. Membr. Sci., 1996, 119, 253-268.

42 C. Bellona and J. E. Drewes, The role of membrane surface charge and solute physico-chemical properties in the rejection of organic acids by NF membranes, J. Membr. Sci., 2005, 249, 227-234.

43 D. Dolar, N. Drasinac and K. Kosutic, Adsorption of hydrophilic and hydrophobic pharmaceuticals on $\mathrm{RO} / \mathrm{NF}$ membranes: identification of interactions using FTIR, $J$. Appl. Polym. Sci., 2017, 134, 44426.

44 L. D. Nghiem, A. I. Schafer and M. Elimelech, Pharmaceutical retention mechanisms by nanofiltration membranes, Environ. Sci. Technol., 2005, 39, 7698-7705.

45 D. Long, M. Nghie and I. Andrea, Pharmaceutical retention mechanisms by nanofiltration membranes, Environ. Sci. Technol., 2005, 39, 7698-7705.

46 C. Labbez, A. Szymczyk and A. Vidonne, Analysis of the salt retention of a titania membrane using the "DSPM" model: effect of $\mathrm{pH}$, salt concentration and nature, J. Membr. Sci., 2002, 208, 315-329.

47 J. E. Kilduff, S. Mattaraj and G. Belfort, Flux decline during nanofiltration of naturally-occurring dissolved organic matter: effects of osmotic pressure, membrane 
permeability, and cake formation, J. Membr. Sci., 2004, 239, 39-53.

48 Q. L. Li and M. Elimelech, Synergistic effects in combined fouling of a loose nanofiltration membrane by colloidal materials and natural organic matter, J. Membr. Sci., 2006, 278, 72-82.
49 A. R. D. Verliefde, E. R. Cornelissen, S. G. J. Heijman, J. Q. J. C. Verberk, G. L. Amy and B. V. Bruggen, The role of electrostatic interactions on the rejection of organic solutes in aqueous solutions with nanofiltration, J. Membr. Sci., 2008, 322, 52-66. 